\title{
NEW BOMB PULSE RADIOCARBON RECORDS FROM ANNUAL TREE RINGS IN THE NORTHERN HEMISPHERE TEMPERATE REGION
}

\author{
G Quarta ${ }^{1} \cdot \mathrm{M}^{\prime} \mathrm{D}^{\prime}$ Elia $・ \mathrm{D}$ Valzano $・$ L Calcagnile \\ Dipartimento di Ingegneria dell'Innovazione, Università di Lecce, via Arnesano, 73100 Lecce, Italy.
}

ABSTRACT. The "bomb" radiocarbon spike induced by atmospheric nuclear detonations has been reconstructed at a latitude of $40^{\circ} \mathrm{N}$ by measuring the ${ }^{14} \mathrm{C}$ content in annual rings of a living pine (Pinus pinea) at the Accelerator Mass Spectrometry facility of the University of Lecce. We report how the samples were taken, selected, prepared for analysis, and measured. The results are in good agreement with other data sets available for the Northern Hemisphere temperate regions, showing that a curve for the calibration of ${ }^{14} \mathrm{C}$ dates, valid for the whole Northern Hemisphere, can be established for the second half of the 20th century.

\section{INTRODUCTION}

The concentration of ${ }^{14} \mathrm{CO}_{2}$ in the atmosphere is a result of natural events, e.g., the production of radioactive carbon dioxide in the stratosphere due to cosmic rays, the stratosphere-troposphere mixing, lateral mixing in the stratosphere, ocean upwelling, exchanges with the terrestrial biosphere, and the radioactive decay of radiocarbon, as well as anthropogenic events like the combustion of fossil fuel and nuclear weapons explosions. For this reason, fluctuations in ${ }^{14} \mathrm{C}$ concentrations in the atmosphere can be used as a tracer for human activity on a local as well as on a global scale. The ${ }^{14} \mathrm{C}$ concentration in tree-ring samples from southern Italy has been measured in order to determine the ${ }^{14} \mathrm{C}$ excess resulting from the nuclear detonations carried out in the atmosphere after World War II. The first aim of the present work was to construct a local calibration curve to be used as a reference for high-resolution ${ }^{14} \mathrm{C}$ dating of recent samples. A comparison of the new data with other data sets already published is intended to make a contribution to the question of whether a bomb peak calibration curve, valid for the whole Northern Hemisphere, can be established.

\section{METHODS: SAMPLE PREPARATION AND AMS MEASUREMENTS}

A medium-sized pine tree (Pinus pinea) grown in an open field in a suburban area surrounding Brindisi in southern Italy (lat $40^{\circ} 65^{\prime} \mathrm{N}$ ) was chosen for the analysis. The sampling location was chosen in an agricultural area where, in the studied time range, no human activities occurred that could influence the ${ }^{14} \mathrm{C}$ concentration in the air.

The samples were taken from the tree using an increment borer of the type normally used in dendrochronological studies, with an outer diameter of $4 \mathrm{~mm}$ and a length of $500 \mathrm{~mm}$. The dendrochronological dating of the rings was accurate because of the clear ring structure of the tree and was verified by ring-width measurements and by comparison with other living pines grown in the same region.

Eighteen samples were selected and prepared for accelerator mass spectrometry (AMS) analysis, with an annual resolution in the peak area between 1959 and 1967. The earlywood of each ring was isolated, split, and then crushed to pieces of about 1-mm length in order to increase the effectiveness of the preparation process. Depending of the ring width, between 20 and $120 \mathrm{mg}$ of sample material was prepared using the common acid-alkali-acid method:

1. Acid attack with $\mathrm{HCl}(10 \mathrm{~mL}, 1 \mathrm{M})$ for $10 \mathrm{hr}$ at room temperature;

2. Rinsing with deionized water to $\mathrm{pH}=5$;

${ }^{1}$ Corresponding author. Email: gianluca.quarta@unile.it. 
3. Alkali attack with $\mathrm{NaOH}(10 \mathrm{~mL}, 1 \mathrm{M})$ at $60{ }^{\circ} \mathrm{C}$;

4. Rinsing with deionized water to $\mathrm{pH}=7$;

5. Acid attack $(10 \mathrm{~mL}, 1 \mathrm{M})$ for $10 \mathrm{hr}$;

6. Rinsing with deionized water.

Since the sample preparation procedure used (AAA) allows the removal only of the soluble fraction of the wood structure but not the separation of the lignin part, which should be more susceptible to contamination than cellulose (Hoper et al. 1998), for some rings the cellulose component was also extracted (Hua et al. 2000) and dated. Since no significant differences were found when comparing the ${ }^{14} \mathrm{C}$ concentration of the insoluble fraction and of the cellulose of the same ring, we think that, at least for the studied samples, the contamination induced in the lignin component is negligible.

The obtained purified material (insoluble fraction) was then dried for 3 days at $60{ }^{\circ} \mathrm{C}$. Approximately $8 \mathrm{mg}$ of pretreated material per sample was selected for combustion to $\mathrm{CO}_{2}$ at $900{ }^{\circ} \mathrm{C}$ in a sealed quartz tube together with $\mathrm{CuO}$ and silver wool. The $\mathrm{CO}_{2}$ sample thus obtained was purified and cryogenically transferred to graphitization cells, where it was reduced to graphite using $\mathrm{H}_{2}$ as the reducing agent and iron powder as the catalyst (D'Elia et al. 2003). Each sample produced enough graphite, $1 \mathrm{mg}$ on average, to allow precise measurements in the accelerator.

The AMS measurements were carried out at the AMS facility of the University of Lecce (Calcagnile et al. 2003) using IAEA C6 (sucrose) standards as a reference and the NIST Oxalic Acid II standard for quality and accuracy control. The ${ }^{14} \mathrm{C} /{ }^{12} \mathrm{C}$ ratios were corrected for sample preparation and accelerator background and normalized for mass fractionation to $-25 \%$ by using the ${ }^{13} \mathrm{C}$ value measured directly with the accelerator (Calcagnile et al., forthcoming). The $\Delta^{14} \mathrm{C}$ value was obtained from the ${ }^{14} \mathrm{C} /{ }^{12} \mathrm{C}$ ratio, after correcting it for the radioactive decay of both the standard and the sample from 1950 and from the year of growth, respectively (Stuiver and Polach 1977; Hajdas 1993).

\section{RESULTS AND DISCUSSION}

The measured $\Delta^{14} \mathrm{C}$ and $\delta^{13} \mathrm{C}$ terms are listed in Table 1 . Figure 1 shows the $\Delta^{14} \mathrm{C}$ values measured for the pine and, for comparison, the tree-ring records from 2 other sites in the Northern Hemisphere: Acacia, Hungary $\left(47^{\circ} 35^{\prime} \mathrm{N}\right)\left(\right.$ Hertelendi et al. 1982), and Arizona, USA $\left(32^{\circ} \mathrm{N}\right)($ Goodsite et al. 2001). Comparison of the plotted curves shows that the tree-ring records obtained for southern Italy follow the general trend observed for the other sites in the temperate Northern Hemisphere, in particular the highest $\Delta{ }^{14} \mathrm{C}$ value as observed in 1964 (Hua et al. 2000) and a small drop in the ${ }^{14} \mathrm{C}$ concentration seen in 1960-1961, which can be explained as the result of a temporary halt to nuclear detonations in that period due to the "Geneva Convention of Experts for the Discontinuance of Nuclear Weapons." Some significant differences in the maximum value of the ${ }^{14} \mathrm{C}$ concentration occur in the time range between 1963 and 1965. In particular, the data obtained for southern Italy fit surprisingly well with the data from Arizona, while the peak value for Hungary is significantly higher. To explain this, the atmospheric circulation has to be taken into account. In particular, several authors (Dai and Fan 1986; Dai et al. 1992; Levin et al. 1985) have tried to explain this effect as a result of a latitudinal gradient in the ${ }^{14} \mathrm{CO}_{2}$ concentration generated by the injection of ${ }^{14} \mathrm{C}$ enriched air into the troposphere from the stratosphere during the tree growing season (from spring to early summer). If this is the case, the ${ }^{14} \mathrm{C}$ concentration in the tree rings should be higher when compared with the annual averaged atmospheric value. In order to check this, we compared our data with the "atmospheric" calibration curve averaged over the whole year (solid line in Figure 1) and that one averaged over the tree growing season (dashed line in Figure 1) as reported by Goodsite et al. (2001). 
Table 1 Measured $\Delta^{14} \mathrm{C}$ and $\delta^{13} \mathrm{C}$ values for the pine (suburban area).

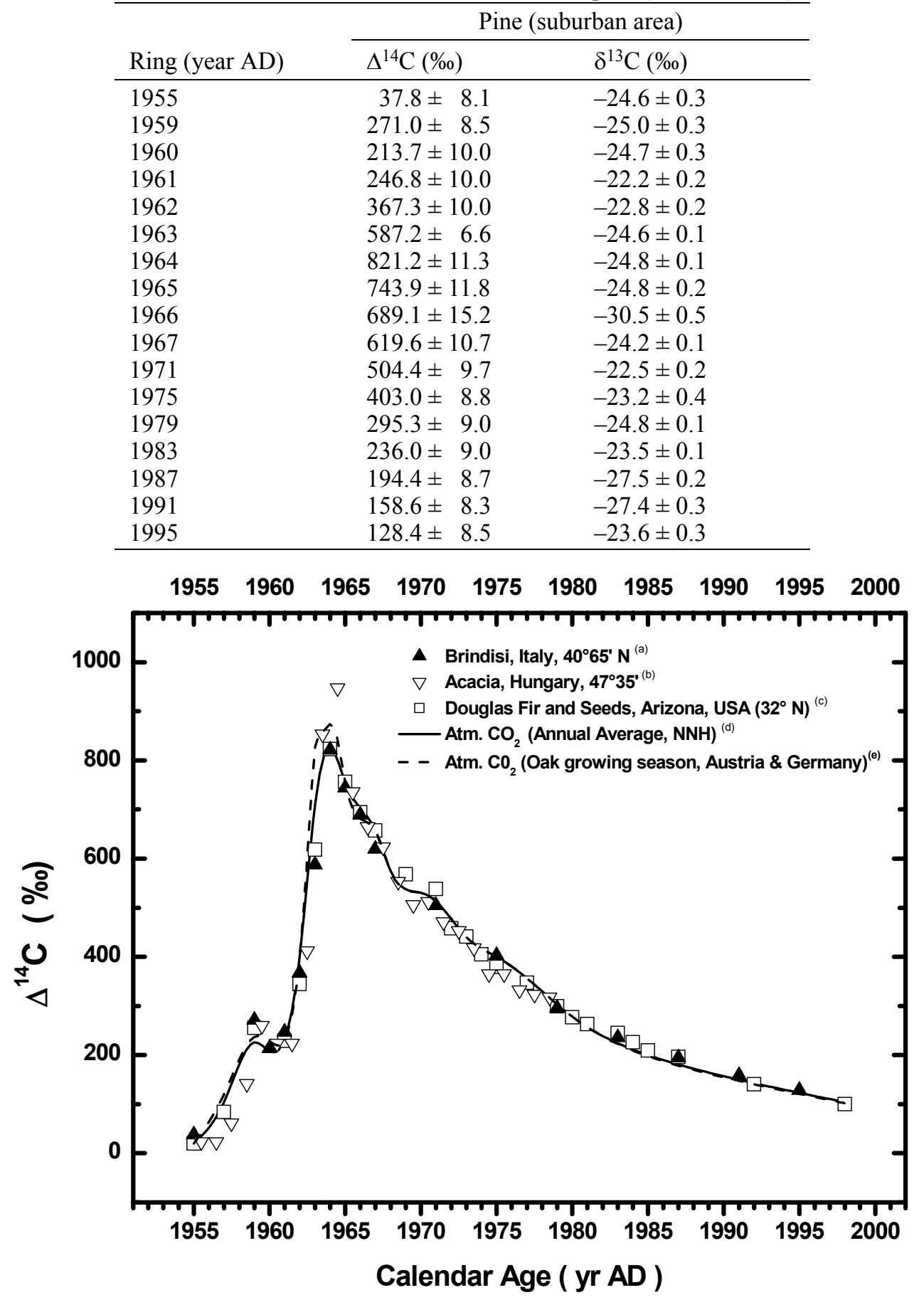

Figure $1{ }^{14} \mathrm{C}$ concentration in tree rings versus the calendar age: a) tree-ring data (insoluble fraction) from a living pine (Pinus pinea) in Brindisi (Italy), $40^{\circ} \mathrm{N}$ (see Table 1); b) tree-ring data from Acacia, Hungary (Hertelendi et al. 1982); c) tree-ring and seeds (Douglas fir and cotton) data from Arizona (USA), $32^{\circ} \mathrm{N}$ (Goodsite et al. 2001); d) annual averaged ${ }^{14} \mathrm{CO}_{2}$ curve for the $30-90^{\circ}$ latitude band (Goodsite et al. 2001); e) atmospheric ${ }^{14} \mathrm{CO}_{2}$ from Austria and Germany $\left(48^{\circ} \mathrm{N}\right)$ (Levin et al. 1997; Goodsite et al. 2001) averaged only for the oak growing season (April to August). 
From Figure 1, it is clear that our data follow the annual averaged "atmospheric" curve very well, and no higher values are observed in the ${ }^{14} \mathrm{C}$ concentration in the tree rings. For this reason, although a latitude dependence is present, these data seem to point towards the absence of seasonal variations related to the injection of air from the stratosphere in the tree growing season at least at the studied latitude. In order to confirm this still preliminary conclusion, other investigations are being carried out by comparing the ${ }^{14} \mathrm{C}$ concentration in the earlywood and latewood portions of the same ring (Olsson and Possnert 1992).

\section{CONCLUSIONS}

A new bomb pulse record has been obtained for southern Italy at a latitude of $40^{\circ} \mathrm{N}$ by measuring the ${ }^{14} \mathrm{C}$ concentration in the rings of a living pine tree (Pinus pinea). The results, which are in good agreement with the data sets already available for other tree-ring records, are intended to contribute to the studies of the atmospheric circulation, of the global carbon cycle, and of the atmosphereoceans interactions. A calibration curve valid for the ${ }^{14} \mathrm{C}$ dates has been also established. As already done by others (Goodsite et al. 2001), it needs to be emphasized that the calibrated ages obtained with the present data sets and those obtained with any of the others already available for the Northern Hemisphere are in good agreement (within 1-2 yr).

\section{ACKNOWLEDGMENTS}

We wish to thank Mr Umberto Toma and Mr Lucio Maruccio for their help during sampling and Prof Livio Ruggiero for the helpful discussions about dendrochronological methods.

\section{REFERENCES}

Calcagnile L, Quarta G, D'Elia M, Rizzo A, Gottdang A, Klein M, Mous DJW. Forthcoming. A new accelerator mass spectrometry facility in Lecce, Italy. In: Proceedings of the 9th AMS Conference, Nagoya, Japan, 2003. Nuclear Instruments and Methods in Physics Research $B$.

Calcagnile L, Quarta G, D'Elia M, Gottdang A, Klein M, Mous DJW. Forthcoming. Radiocarbon precision tests at the Lecce AMS facility using a sequential injection system. Nuclear Instruments and Methods in Physics Research $B$.

Day KM, Fan CY. 1986. Bomb-produced ${ }^{14} \mathrm{C}$ content in tree rings grown at different latitudes. Radiocarbon 28(2A):346-9.

Day KM, Quian Y, Fan CY. 1992. Bomb-produced ${ }^{14} \mathrm{C}$ in tree rings. Radiocarbon 34(3):753-6.

D’Elia M, Calcagnile L, Quarta G, Sanapo C, Laudisa M, Toma U, Rizzo A. Forthcoming. Progress at the sample preparation laboratory of the Lecce AMS facility. In: Proceedings of the 9th AMS Conference, Nagoya, Japan, 2003. Nuclear Instruments and Methods in Physics Research B.

Goodsite ME, Rom W, Heinemeier J, Lange T, Ooi S, Appleby PG, Shotyk W, van der Knaap WO, Lohse C, Hansen TS. 2001. High-resolution AMS ${ }^{14} \mathrm{C}$ dating of post-bomb peat archives of atmospheric pollutants.
Radiocarbon 43(2B)495-515.

Hajdas I. 1993. Extension of the radiocarbon calibration curve by AMS dating of laminated sediments of Lake Soppensee and Lake Holzmar [PhD dissertation]. Zürich: Eidgenössische Technische Hochschule.

Hertelendi E, Csongor E. 1982. Anthropogenic ${ }^{14} \mathrm{C}$ excess in the troposphere between 1951 and 1978 measured in tree rings. Radiochemical and Radioanalytical Letters 56:103-10.

Hoper ST, McCormac FG, Hogg AG, Higham TFG, Head MJ. 1998. Evaluation of wood pretreatments on oak and cedar. Radiocarbon 40(1):45-50.

Hua Q, Barbetti M, Jacobsen GE, Zoppi U, Lawson EM. 2000. Bomb radiocarbon in annual tree rings from Thailand and Tasmania. Nuclear Instruments and Methods in Physics Research B 172:359-65.

Levin I, Kromer B, Schoch-Fisher H, Bruns M, Münich M, Berdau D, Vogel JC, Münich KO. 1985. 25 years of tropospheric ${ }^{14} \mathrm{C}$ observations in central Europe. Radiocarbon 27(1):1-19.

Olsson IU, Possnert G. $1992 .{ }^{14} \mathrm{C}$ activity in different sections and chemical fractions of oak tree rings, $\mathrm{AD}$ 1938-1981. Radiocarbon 34(3):757-67.

Stuiver M, Polach HA. 1977. Discussion: reporting of ${ }^{14} \mathrm{C}$ data. Radiocarbon 19(3):355-63. 